\title{
Substraksi RGB untuk Identifikasi Jenis Daging Konsumsi Berbasis Pengolahan Citra
}

\author{
Afri Yudamson ${ }^{1}$, Sri Ratna Sulistiyanti ${ }^{2}$, Syaiful Alam $^{3}$, FX. Arinto Setyawan ${ }^{4}$, Titin Yulianti ${ }^{5}$ \\ Jurusan Teknik Elektro, Fakultas Teknik Universitas Lampung \\ Jl. Prof. Sumantri Brojonegoro No. 1 Gedong Meneng Bandar Lampung \\ 1afri.yudamson@eng.unila.ac.id \\ ${ }^{2}$ sr sulistiyantideng.unila.ac.id \\ ${ }^{3}$ syaiful.alam@eng.unila.ac.id \\ ${ }^{4} \mathrm{fx} \cdot \mathrm{arinto@eng} \cdot$ unila.ac.id \\ 5titin.yulianti@eng.unila.ac.id
}

Intisari - Kesenjangan nilai ekonomis yang cukup tinggi yang terjadi pada komoditas beberapa jenis daging konsumsi menjadi penyebab utama terjadinya kecurangan pada proses penjualannya. Secara kasat mata, beberapa jenis daging akan terlihat sama sehingga sulit untuk diidentifikasi. Dengan menggunakan pengolahan citra, data matriks dari beberapa jenis daging konsumsi akan menampilkan kecenderungan tertentu sehingga dapat dijadikan ciri identifikasi. Sampel pada penelitian ini adalah daging Kambing, daging Anjing, daging Babi, dan daging Celeng. Metode Substraksi RGB merupakan turunan dari matriks citra RGB. Dengan menggunakan metode ini, citra masing-masing jenis daging konsumsi dapat diidentifikasi. Hasil penelitian menunjukkan bahwa daging Kambing dan daging Celeng dapat diidentifikasi menggunakan substraksi GB, sedangkan daging Anjing dan daging Babi dapat diidentifikasi menggunakan substraksi GB yang dilanjutkan dengan substraksi RB.

Kata kunci - kecurangan penjualan daging, identifikasi daging, pengolahan citra, substraksi RGB

Abstract - High gap of the economic values that occurs in several types of meat commodities is a major cause of fraud of the meat sales. In plain view, several types of meat will be look similar so these were difficult to identify. By using image processing, matrix data from several types of meat will display certain trends so that it can be used as an identification feature. Samples in this study were goat meat, dog meat, pork meat, and boar meat. The RGB Substraction Method is a derivative of an RGB image matrix. Using this method, images of each type of meat can be identified. The results showed that goat meat and boar meat could be identified using GB substraction, while dog meat and pork meat could be identified using GB substraction followed by RB subtraction.

Keywords - meat sales fraud, meat identification,image processing, RGB substraction 


\section{PENDAHULUAN}

Daging merupakan komoditas dengan nilai ekonomis yang cukup tinggi. Hal ini menyebabkan terjadinya kecurangan pada proses jual beli daging konsumsi. Kecurangan itu dilakukan dengan cara mencampur beberapa jenis daging konsumsi yang berbeda dan diklaim sebagai daging dengan nilai ekonomis yang paling tinggi. Kesenjangan nilai ekonomis yang cukup besar merupakan alasan utama kecurangan tersebut [1].

Beberapa jenis daging, secara kasat mata terlihat seolah merupakan jenis daging yang sama. Secara umum, daging berwarna merah. Namun, jika ditelaah menggunakan pengolahan citra maka akan menghasilkan nilai yang berbeda untuk setiap jenis daging. Artikel ini memaparkan hasil penelitian yang bertujuan mengidentifikasi beberapa jenis daging konsumsi dengan proses pengolahan citra menggunakan metode substraksi RGB.

Beberapa penelitian terdahulu telah banyak dilakukan. Kiswanto telah dapat mengidentifikasi citra daging sapi menggunakan transformasi wavelet haar [2]. Selanjutnya, Julia Rosmaya Riasari telah meneliti tentang perbedaan karakteristik daging sapi dengan daging babi [1]. Elvia Budianita telah meneliti tentang implementasi pengolahan citra dan klasifikasi K-Nearest Neighbour untuk membangun aplikasi pembeda daging sapi dan babi [3]. Dedy Yuristiawan telah melakukan penelitian tentang aplikasi pendeteksi tingkat kesegaran daging sapi lokal menggunakan ekstraksi fitur warna dengan pendekatan statistika [4].

\section{METODE}

Penelitian ini dilakukan dengan beberapa tahapan sebagai berikut:

\section{A. Akuisisi Data Citra}

Akuisisi data dimulai dari pengirisan daging. Kemudian dilanjutkan dengan penentuan tata letak daging seluruh peralatan yang digunakan pada pengambilan data citra. Penentuan ini dilakukan agar data citra yang diambil memenuhi standar sehingga dapat memudahkan dalam pengolahan citra lebih lanjut. Daging yang digunakan pada penelitian ini adalah daging kambing, daging anjing, daging babi, dan daging celeng.

\section{B. Image Pre-processing}

Proses ini terdiri dari segmentation, cropping, dan resizing. Segmentation dimaksudkan agar background tercuplik yang bukan merupakan citra daging dapat dibedakan dan dihilangkan dan kemudian dapat menjadi acuan untuk proses cropping. Cropping dimaksudkan agar citra yang diolah hanya berupa citra daging sehingga tidak ada data kosong/background. Resizing dilakukan agar memori yang digunakan dalam pengolahan citra dapat mencapai nilai optimal.

\section{Image identification}

Proses ini dilakukan untuk menentukan variable apa saja yang mempengaruhi jenis daging dari segi warna. Variable yang dapat diasumsikan tidak berpengaruh pada jenis daging akan dieliminasi. Selanjutnya masing-masing variable yang terpilih akan dianalisis untuk penentuan threshold sebagai penanda pengklasifikasi citra. Variable yang menjadi pilihan dalam penelitian ini berdasarkan dari masing-masing matriks substraksi RG, RB, dan GB. Dari variable-variabel tersebut kemudian ditentukan batas ambang untuk mengidentifikasi jenis daging yang berbeda.

\section{HASIL DAN PEMBAHASAN}

Citra sampel diambil menggunakan kamera android dengan ditentukan kisaran jarak pangambilannya. Gambar 1 adalah beberapa citra dari empat jenis daging berbeda setelah melalui pre-processing. Bagian berwarna merah adalah data citra yang akan diproses dalam tahap berikutnya sedangkan bagian berwarna hitam adalah data yang nilainya diabaikan. Selanjutnya nilai parameter substraksi RGB dihitung untuk masingmasing citra sampel. Gambar 2 menunjukkan hasil substraksi RGB untuk masing-masing kelompok jenis daging.

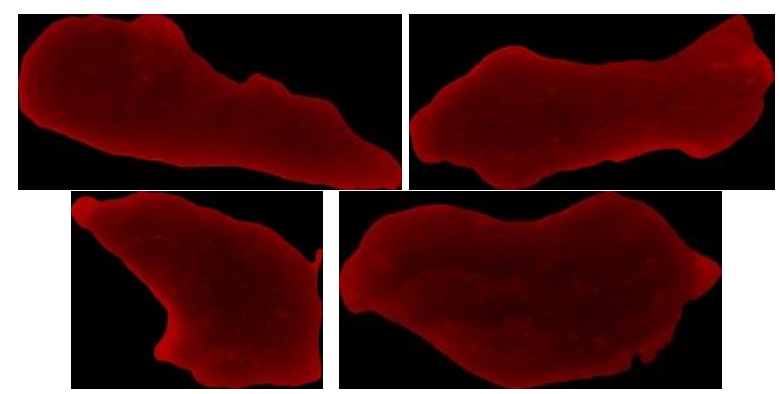

(a) 


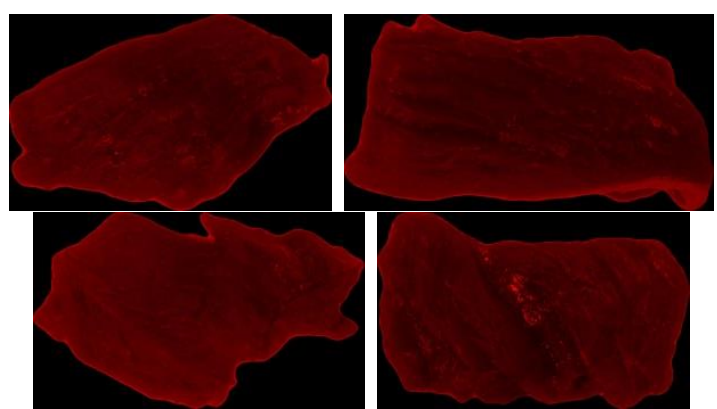

(b)

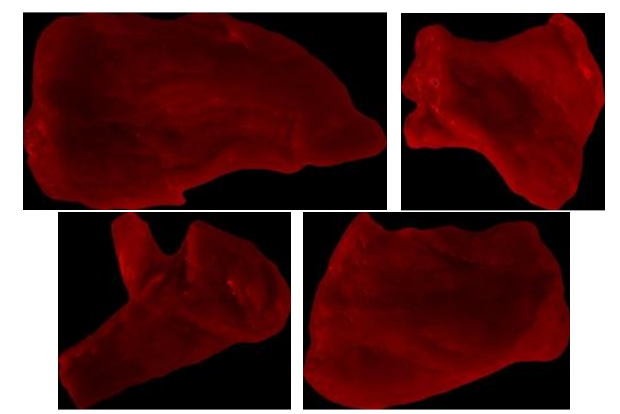

(c)

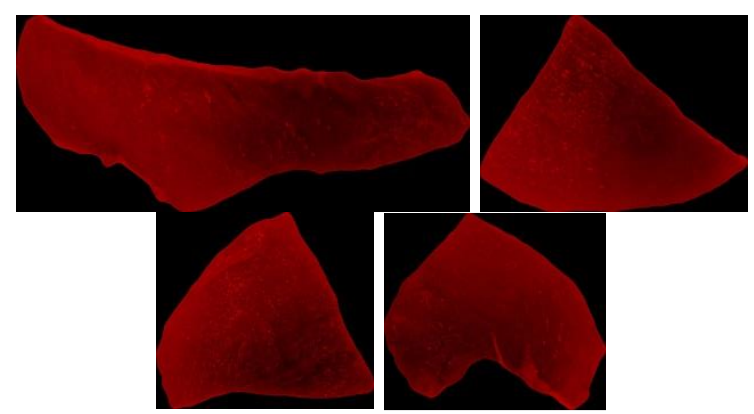

(d)

Gbr.1 Citra Daging setelah pre-processing: (a) Daging Kambing, (b) Daging Anjing, (c) Daging Babi, (d) Daging Celeng

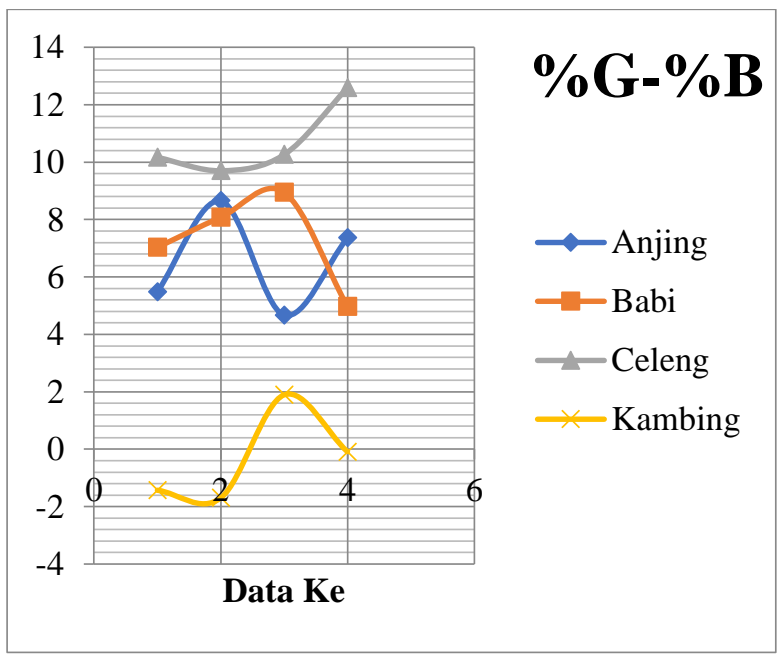

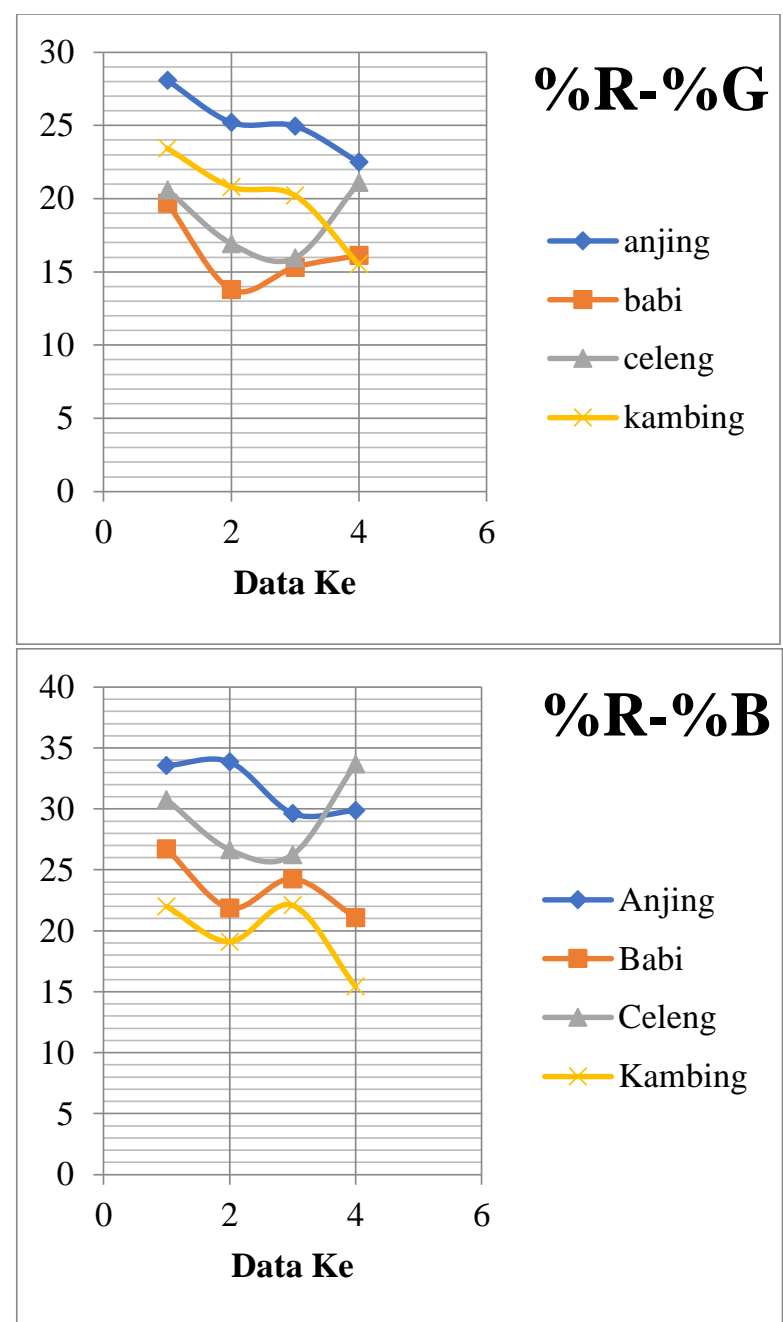

Gbr.2 Grafik Substraksi RGB

Gambar 2 terdiri dari 3 buah grafik yaitu grafik substraksi GB (\%G-\%B), grafik substraksi RB (\%R-\%B), dan grafik substraksi RG (\%R-\%G). Grafik \%G-\%B menunjukkan bahwa tidak terdapat irisan data daging Celeng dengan data jenis daging lainnya serta tidak terdapat irisan data daging Kambing dengan jenis daging lainnya. Dengan demikian, ciri daging Kambing dan daging Celeng dapat diambil pada substraksi $\% \mathrm{G}-\% \mathrm{~B}$ menggunakan batas ambang (Threshold) masing-masing. Data daging Babi dan Anjing saling beririsan pada substraksi \%G-\%B sehingga belum dapat dijadikan sebagai ciri identifikasi. Substraksi $\%$ R-\%B menunjukkan bahwa data daging Babi dan daging Anjing tidak saling beririsan. Hal ini juga terjadi pada substraksi \%R-\%G. Namun, jarak yang lebih besar terdapat pada substraksi \%R-\%B. Dengan demikian ciri identifikasi daging Babi maupun daging 
Anjing dapat diambil melalui threshold untuk substraksi $\% \mathrm{G}-\% \mathrm{~B}$ yang dilajutkan dengan threshold untuk substraksi \%R-\%B.

Tabel 1 memperlihatkan nilai maksimal dan minimal substraksi RGB untuk masingmasing jenis daging. Threshold untuk identifikasi daging Celeng adalah 9,7\% sampai dengan $12,59 \%$ pada substraksi GB. Threshold untuk identifikasi daging Kambing adalah $-1,69 \%$ sampai dengan $1,88 \%$ pada substraksi GB. Threshold untuk identifikasi daging Babi adalah 4,96\% sampai dengan $8,94 \%$ pada substraksi GB dan 21,09\% sampai dengan $26,71 \%$ pada substraksi RB. Threshold untuk identifikasi daging Anjing adalah 4,67\% sampai dengan $8,65 \%$ pada substraksi GB dan 29,63\% sampai dengan $33,86 \%$ pada substraksi RB.

Table 1. Rekapitulasi nilai Maksimal dan Minimal Ekstraksi Citra ke RGB

\begin{tabular}{lcccc}
\hline \multicolumn{1}{c}{$\begin{array}{c}\text { Jenis } \\
\text { Daging }\end{array}$} & Nilai & $\begin{array}{c}\text { \% G- } \\
\text { \% B }\end{array}$ & $\begin{array}{c}\text { \% R- } \\
\text { \% B }\end{array}$ & $\begin{array}{c}\text { \% R- } \\
\text { G }\end{array}$ \\
\hline $\begin{array}{l}\text { Daging } \\
\text { Kambing }\end{array}$ & Maksimal & 1,88 & 22,1 & 23,43 \\
\cline { 2 - 5 } & Minimal & $-1,69$ & 15,43 & 15,52 \\
\hline $\begin{array}{l}\text { Daging } \\
\text { Anjing }\end{array}$ & Maksimal & 8,65 & 33,86 & 28,07 \\
\cline { 2 - 5 } & Minimal & 4,67 & 29,63 & 22,49 \\
\hline $\begin{array}{l}\text { Daging } \\
\text { Babi }\end{array}$ & Maksimal & 8,94 & 26,71 & 19,67 \\
\cline { 2 - 5 } & Minimal & 4,96 & 21,09 & 13,78 \\
\hline $\begin{array}{l}\text { Daging } \\
\text { Celeng }\end{array}$ & Maksimal & 12,59 & 33,69 & 21,1 \\
\cline { 2 - 5 } & Minimal & 9,7 & 26,23 & 15,96 \\
\hline
\end{tabular}

\section{KESIMPULAN}

Kesimpulan yang dapat diambil dari hasil penelitian ini antara lain:

1. Parameter identifikasi daging Kambing dapat diambil dari substraksi GB dengan threshold -1,69\% sampai dengan 1,88\%.

2. Parameter identifikasi daging Celeng dapat diambil dari substraksi GB dengan threshold $9,7 \%$ sampai dengan $12,59 \%$.
3. Parameter identifikasi daging Anjing dapat diambil dari substraksi GB dengan threshold 4,67\% sampai dengan $8,65 \%$ dan $29,63 \%$ sampai dengan $33,86 \%$ pada substraksi RB.

4. Parameter identifikasi daging Babi dapat diambil dari substraksi GB dengan threshold 4,96\% sampai dengan 8,94\% pada substraksi $\% \mathrm{G}-\% \mathrm{~B}$ dan $21,09 \%$ sampai dengan $26,71 \%$ pada substraksi RB.

\section{UCAPAN TERIMA KASIH}

Terima kasih kepada Lembaga Penelitian dan Pengabdian kepada Masyarakat (LPPM) Universitas Lampung yang telah memberikan dukungan melalui Hibah Penelitian Dosen Pemula Tahun Anggaran 2019 dengan Surat Perjanjian Pelaksanaan No: 2615/UN26.21/PN/2019 tanggal 4 Juli 2019.

\section{REFERENSI}

[1] Riasari, Julia Rosmaya, 2014. Perbedaan Karakteristik Daging Sapi dan Daging Babi. Institut Pertanian Bogor.

[2] Kiswanto, 2012. Identifikasi Citra untuk Mengidentifikasi Jenis Daging Sapi dengan Menggunakan Transformasi Wavelet Haar.Tesis Magister Sistem Informasi Universitas Diponegoro Semarang.

[3] Budianita, Elvia, dkk, 2015. Implementasi Pengolahan Citra dan Klasifikasi K-Nearest Neighbour Untuk Membangun Aplikasi Pembeda Daging Sapi dan Babi. Jurnal Sains, Teknologi dan Industri, Vol. 12, No. 2, Juni 2015, pp.242 - 247 ISSN 1693-2390 print/ISSN 2407-0939 online.

[4] Yuristiawan, Dedy, 2015. Aplikasi Pendeteksi Tingkat Kesegaran Daging Sapi Lokal Menggunakan Ekstraksi Fitur Warna dengan Pendekatan Statistika. Riptek Vol. 9, No. 1, Tahun 2015, Hal. 9 - 16.S. M. Hemmingsen, Soft Science. Saskatoon: University of Saskatchewan Press, 1997. 